\title{
Allelopathic Effects of Three Herb Species on Phytophthora cinnamomi, a Pathogen Causing Severe Oak Decline in Mediterranean Wood Pastures
}

\author{
Manuela Rodríguez-Romero ${ }^{1,2, *(1)}$, Belén Godoy-Cancho ${ }^{1}$, Isabel M. Calha ${ }^{3}$, José António Passarinho ${ }^{3}$ and \\ Ana Cristina Moreira ${ }^{3}$ \\ 1 Centro de Investigaciones Científicas y Tecnológicas de Extremadura (CICYTEX)/Instituto del Corcho, \\ la Madera y el Carbón Vegetal (ICMC), Junta de Extremadura, Pol. Ind. El Prado, C/Pamplona s/n, \\ 06800 Mérida, Spain; belen.godoy@juntaex.es \\ 2 Instituto de Investigación de la Dehesa (INDEHESA), Universidad de Extremadura (UEX), \\ Av. Virgen del Puerto s/n, 10600 Plasencia, Spain \\ 3 Instituto Nacional de Investigação Agrária e Veterinária (INIAV, IP), Quinta do Marquês, \\ 2784-505 Oeiras, Portugal; isabel.calha@iniav.pt (I.M.C.); jose.passarinho@iniav.pt (J.A.P.); \\ cristina.moreira@iniav.pt (A.C.M.) \\ * Correspondence: manuela.rodriguez@juntaex.es
}

check for updates

Citation: Rodríguez-Romero, M.; Godoy-Cancho, B.; Calha, I.M.; Passarinho, J.A.; Moreira, A.C. Allelopathic Effects of Three Herb Species on Phytophthora cinnamomi, a Pathogen Causing Severe Oak Decline in Mediterranean Wood Pastures. Forests 2021, 12, 285. https://doi.org/10.3390/f12030285

Academic Editor: Fred O. Asiegbu

Received: 10 December 2020

Accepted: 25 February 2021

Published: 2 March 2021

Publisher's Note: MDPI stays neutral with regard to jurisdictional claims in published maps and institutional affiliations.

\begin{abstract}
The ability of three herbaceous plants (Diplotaxis tenuifolia (L.) DC., Eruca vesicaria L. and Raphanus raphanistrum L.) from Iberian wood pastures to reduce Phytophthora cinnamomi Rands pathogen populations through allelopathic relationships is studied. The inhibitory capacity of their aqueous root extracts (AREs) on mycelial growth and production of P. cinnamomi reproductive structures is analysed in vitro. In addition, Quercus seedlings were grown in infested by P. cinnamomi-soils and with the presence or absence of allelopathic and susceptible herb species to the pathogen to assess the defensive chemical response of Quercus seedlings through their leaf phenolic compounds. Results show a strong inhibitory capacity of AREs on P. cinnamomi activity in vitro and a protective effect of these herb species on Quercus plants against P. cinnamomi in vivo. D. tenuifolia would be especially suited for biological control in the pathogen suppression.
\end{abstract}

Keywords: allelopathy; biocontrol; dehesa and montado's herb species; Phytophthora cinnamomi; Quercus decline

\section{Introduction}

Plants can influence the composition of microbial communities around their roots through exudation of carbohydrates and other allelopathic compounds. Allelopathy is a naturally occurring ecological phenomenon of interference among organisms by which one of them produces one or more biochemical compounds that influence the growth and development of others (bacteria, fungi, plants ... ), either negatively or positively [1-3]. Some exudates present bactericidal and fungicidal activity and can affect the growth, survival and/or reproduction of various microorganisms. The allelochemicals most frequently involved in these fungicidal relationships are secondary metabolites that are not directly involved in the plant life cycle but play an important role in its defence against natural enemies. Allelochemicals are located in different parts of the plant, such as leaves, branches or roots [4]. They are usually released directly into the aqueous phase of the soil, or from volatile gaseous substances in the surrounding air [5]. The allelochemical release is influenced by the soil, climatic conditions and the plant itself [6].

Iberian agrosilvopastoral ecosystems are currently suffering an increasing decline with serious impact on oak species. The widespread Quercus decline is influenced by the action of biotic and abiotic stress factors. This disease is associated with different species of oomycetes and Phytophthora cinnamomi Rands is the most frequently isolated 
from the Iberian Peninsula soils [7]. This soil-borne pathogen affects more than 5000 trees, shrubs and herbs species in the world [8] and causes root rot and death of several Quercus species. Its eradication from the soil in field is very complex due to the durability of its resistance structures and the easy spread by different pathways [9]. Nowadays, the control is understood only from an integrated perspective, given its wide dispersion and the large host range. Especially susceptible are holm oak (Q. ilex L.) and cork oak (Q. suber L.), which are main tree components of Iberian wood pastures. The Portuguese oak (Q. faginea) is also susceptible to P. cinnamomi, although less than the first two [10-12]. The main chemical defences in Quercus are phenolic compounds and their induction before the attack of biotic stressors has been studied before $[13,14]$, so they can be used to evaluate the damage caused in plants. However, allelopathic phenomena in the co-occurring plants could mitigate the stress caused in Quercus species [15]. The chemical defence levels in Quercus leaves would be a measure of the strength of the host's response to the pathogen.

Among the different management tools against oak decline, biological control is presented as a still underdeveloped alternative but with certain advances in agricultural systems that could be the basis for the development of a forestry strategy [16]. There are species that show resistance to it and even inhibit its infective activity due to the release of allelochemicals [17]. In the Mediterranean flora there are various species with allelopathic effects against $P$. cinnamomi [18-22]. The allelopathic property can be observed in plants used for biofumigation such as Brassica carinata and B. juncea $[19,20,22]$ and in other native flora still under study $[18,19,21]$. The family to which they all belong, Brassicaceae, stands out for its high concentration of glucosinolates, which show fungicidal effect in certain concentrations and conditions $[19,23,24]$. These are sulfur compounds with proven fungicidal and biocidal capacity $[25,26]$. Their defensive properties are generated by an enzymatic hydrolysis that releases volatile compounds, among which are isothiocyanates, nitriles, thiocyanates and oxazolidines, depending on the structure of the original glucosinolate [27].

Based on the findings described by Sampaio [18] and Moreira et al. [21], three herbaceous species from the Mediterranean native flora with potential allelopathic effect facing P. cinnamomi were used in this study for in vitro and in vivo experiments.

The work aims to answer the following questions:

1) What plant species have the greatest allelopathic ability on P. cinnamomi by application of their AREs under in vitro conditions?

2) Do these herb species reduce the need to invest in chemical defences of Quercus seedlings under in vivo conditions when they grow up together in P. cinnamomiinfested soil?

\section{Materials and Methods}

\subsection{Biological Material}

The Phytophthora cinnamomi strain 5833 mating type A2 was isolated from chestnut (Castanea sativa Mill.) roots in central Portugal. Isolation and culture maintenance took place on V8 Juice agar medium as described by Moreira-Marcelino [28].

Root extracts were prepared using 40-day-old plants of Diplotaxis tenuifolia (L.) DC., Eruca vesicaria (L.) Cav. and Raphanus raphanistrum L. A natural soil collected in Sintra, Lisbon, was sown with seeds of these species collected in natural conditions (E. vesicaria and $R$. raphanistrum) and adquired in the market (D. tenuifolia). Plants grew under greenhouse conditions without fertilization and watered twice a week in Oeiras (INIAV) (Portugal, UTM Zone 29S X: 472148, Y: 4283072, $38 \mathrm{~m}$ above sea level). At harvest, the roots were washed to remove the soil and later they were cut to be frozen at $-10^{\circ}$ until processed. The upper part of the plants was discarded.

Acorns of Quercus suber (cork oak) and Q. faginea (Portuguese oak) were collected in forest areas across the Counties of Ourique and Mafra (Portugal). These acorns were used to produce Quercus seedlings to assess the allelopathic effect of the herbaceous species in vivo. 


\subsection{Root Extracts Preparation Using Different Methods and Chemical Characterization}

All glucosinolates occur in the plant in conjunction with the hydrolytic isoenzyme myrosinase, and are located in separate cells [29]. However, after trituration of plant tissues, they come together, so the enzyme must be inactivated to assess the glucosinolate effect. In attempt to inactivate the myrosinase, aqueous root extracts (AREs) were prepared by three different methods. The methods were (M1) maceration of fresh material without inactivation of enzymes (modified from Alkhail [30]), (M2) maceration of fresh material with heat inactivation of enzymes [14,18] and (M3) microwave dried material (modified from Hongju [29]).

AREs were prepared from $10 \mathrm{~g}$ of previously washed roots, with later maceration in $100 \mathrm{~mL}$ distilled water at room temperature in M1. In M2, $10 \mathrm{~g}$ fresh weight was macerated in $100 \mathrm{~mL}$ distilled water at $80^{\circ} \mathrm{C}$ for $10 \mathrm{~min}$ for its inactivation by heat. In the M3 method, after weighing $10 \mathrm{~g}$ of roots, they were microwaved at $900 \mathrm{~W}$ for different times depending on their thickness and humidity (R. raphanistrum $9 \mathrm{~min}, E$. vesicaria $2 \mathrm{~min}, D$. tenuifolia $1 \mathrm{~min})$. Once dry, roots were crushed and macerated at room temperature with $100 \mathrm{~mL}$ distilled water. In all three methods, the solution was filtered and centrifuged for $10 \mathrm{~min}$ at $8000 \times g$ and $4{ }^{\circ} \mathrm{C}$. The supernatant was removed and filtered with Millex-GP $0.22 \mu \mathrm{m}$ (33 mmØ) filters (Merck Millipore Ltd., Carrigtwohill, Cork, IRL). AREs were frozen at $-10{ }^{\circ} \mathrm{C}$ for conservation.

\subsection{In Vitro Assessment of the Allelopathic Effect on the Activity of P. cinnamomi}

The AREs' inhibitory effect on P. cinnamomi activity was evaluated in vitro. The mycelial growth was measured in Petri dishes with V8 broth and ARE at $75 \%(v / v)$ as described Moreira et al. [21], 12 days after their incubation at $25^{\circ} \mathrm{C}$ in the dark. Then, the mycelium was harvested from the broth, filtered, washed and dried in an oven for $48 \mathrm{~h}$ at $60{ }^{\circ} \mathrm{C}$. The dry weight mycelium was recorded. Plates with V8 broth and $75 \%(v / v)$ of sterile water was used as control.

The effect of ARE obtained by M2 was evaluated in the sporangia production, zoospore release and germination and in the production of chlamydospores. The production of $P$. cinnamomi reproductive structures was obtained and analysed using non-sterile soil extract [28] with root extracts at 75\% $(v / v)$. V8-agar plugs (5) $5 \mathrm{~mm}$ in diameter were transferred from the edge of P. cinnamomi colony to the non-sterile soil extract supplemented with ARE and incubated at room temperature with indirect light. Plates were scored at six and 12 days later. Zoospores germination was evaluated using a zoospore suspension $(100 \mu \mathrm{L})$ with $8.0 \times 10^{4} \mathrm{cel} / \mathrm{mL}$, plated on V8-agar $5 \%$ supplemented with ARE at $75 \%$ $(v / v)$ in sterile distilled water and incubated at $25{ }^{\circ} \mathrm{C}$ in the dark. A treatment without ARE and supplemented with sterile distilled water at $75 \%(v / v)$ served as a control. The colony-forming units were counted after $24 \mathrm{~h}$ and $48 \mathrm{~h}$ and the inhibition determined $48 \mathrm{~h}$ after plating. Sporangia and chlamydospores quantification was recorded as the mean number per $\mathrm{mm}^{2}$ at four equidistant spots on the mycelium at $10 \times, 40 \times$ and $100 \times$ under a microscope. All trials had six repetitions per method and species. For the evaluation and taking of photographs of the different $P$. cinnamomi structures, samples were stained with lactophenol blue solution.

The percentage inhibition of P. cinnamomi was calculated as described by Moreira et al. [21], according to the equation: Inhibition $(\%)=100$ (Control-Treatment)/Control. Data were transformed according to the equation: Inhibition $_{\text {transformed }}=(100$-Inhibition $(\%)) / 100$ to satisfy tests of normality. Transformed data were statistically analysed by ANOVA using the Tukey's test $(p<0.05)$ for differentiation of means. Statistical analyses were performed using the Statistica v10 software (StatSoft, Inc., Tulsa, OK, USA). 


\subsection{In Vivo Evaluation of the Effect of Allelopathic Herbaceous Species on Quercus Seedlings in P. cinnamomi-Infested Soil}

The inhibitory effect of E. vesicaria and D. tenuifolia against P. cinnamomi was tested in vivo at INIAV greenhouses in Oeiras. Acorns of $Q$. suber and $Q$. faginea were sown in pots (10 L; two acorns per pot, without mixing Quercus species in each pot) with soil naturally infested with P. cinnamomi. The soil was collected in December in a cork oak woodland located in Biscainho, Coruche (Portugal, UTM Zone 29S X: 532757, Y: 4306056, 71 m above sea level; soil pH: 4.9). In this area, several foci were detected in 2016, showing trees with symptoms of decline infected by P. cinnamomi. The soil was collected from an area where the trees died. Presence of P. cinnamomi in soil was confirmed by its isolation using cork oak young leaves as baits and plated in PARPH selective agar medium [31]. Furthermore, $P$. cinnamomi inoculum was reinforced with $10 \mathrm{~g}$ per pot of inoculum composed by millet seeds (Panicum milliaceum L.) colonized during three weeks by an equal mixture of the three isolates P. cinnamomi 1538,1539 and 5833, incubated at $25^{\circ} \mathrm{C}$ in dark, according to the protocol described by Moreira-Marcelino [28]. The control experiment was prepared in the same way, but using sterilized seeds of $P$. milliaceum. This assay was carried out with three treatments: (1) Quercus species and E. vesicaria and D. tenuifolia; (2) Quercus species and Lupinus luteus; (3) only Quercus species (control). In the first treatment, 12 plants/pot of E. vesicaria and D. tenuifolia (high allelopathic effect on P. cinnamomi) were sown in containers with acorns of the Quercus species. Ten seeds/pot of L. luteus (highly susceptible to $P$. cinnamomi and used as a positive control), were sown in each pot with acorns of the Quercus species. There were five replicates for each species and treatment. After sowing, the three treatments were grown for two years before leaf harvest. Then, 7-9 leaves from each Quercus seedling were collected per pot to quantify their chemical phenolic defences [14,15]. It is assumed that this effect will be the combined action of herbaceous root exudates, together with possible interspecific competition relationships and even the facilitation of bacterial complexes in the soil. Thus, this in vivo essay attempts to be an approach to better understand the role that allelopathic relationships of herbaceous plants play on trees on P. cinnamomi-infected Iberian wood pastures.

\section{Extraction and Quantification of Phenolic Content in Quercus Leaves}

For the determination of defensive phenolic content as described by Gallardo et al. [14], Quercus leaves were lyophilized using a Telstar LyoQuest lyophilizer (temperature $-55^{\circ} \mathrm{C}$ and 0.001-0.002 mbar pressure; Telstar, Terrassa, Spain) and ground to a fine particle size. The phenolic content was extracted from lyophilized material with $70 \%(v / v)$ aqueous methanol for $60 \mathrm{~min}$ in an ultrasonic bath at room temperature. The crude extracts were centrifuged at $8000 \times g$ for $5 \mathrm{~min}$ at $4{ }^{\circ} \mathrm{C}$ and the supernatant was collected and stored at $-80^{\circ} \mathrm{C}$.

The total phenolics content (TPC) was determined by the Folin-Ciocalteu method [32]. Crude extracts (2 volumes) were mixed with 2 volumes of Folin-Ciocalteu reagent (Merck KGaA, Darmstadt, Germany) and 40 volumes of $75 \mathrm{~g}$ per liters of sodium carbonate. In the control tube, the extract volume was replaced by deionized water. The mixture was stirred gently and maintained in the dark and at room temperature for $60 \mathrm{~min}$. After incubation, the absorbance was measured at $670 \mathrm{~nm}$, using a UV/Vis Varian Cary-50 spectrophotometer (Palo Alto, CA, USA). Gallic acid (Sigma-Aldrich, Merck KGaA, Darmstadt, Germany) was used as standard and results were expressed as micrograms of gallic acid equivalents (G.A.E.) per milligrams of lyophilized sample.

The total tannin content (TTC) was determined by the Folin-Denis method [33]. Crude extracts ( 2 volumes) were mixed with 2 volumes of Folin-Denis reagent (Panreac, Barcelona, Spain) and 5 volumes of $200 \mathrm{~g}$ per liters of sodium carbonate. In the control tube, the extract volume was replaced by deionized water. The mixture was stirred gently and maintained in the dark and at room temperature for $30 \mathrm{~min}$. After incubation, the absorbance was measured at $760 \mathrm{~nm}$. Tannic acid (Panreac, Barcelona, Spain) was used as standard and 
results were expressed as micrograms of tannic acid equivalents (T.A.E.) per milligrams of lyophilized sample.

The butanol- $\mathrm{HCl}$ assay [34] was used to quantify condensed tannins (CTC) using procyanidin B2 (Sigma-Aldrich, Madrid, Spain) as a reference compound. Briefly, crude extracts were mixed with 100 volumes of n-butanol/acetone 1:1 (46\% each) plus $\mathrm{HCl}(1.85 \%)$ and ferric ammonium sulphate $(0.04 \%)$. In the control tube, the extract volume was replaced by methanol. Samples were heated at $70{ }^{\circ} \mathrm{C}$. After $45 \mathrm{~min}$ of incubation, the samples were cooled and the absorbance at $550 \mathrm{~nm}$ was measured, with final results expressed as micrograms of procyanidin B equivalents (PB.E.) per milligrams of lyophilized sample.

Antioxidant activity (AA) and the half maximal inhibitory concentration $\left(\mathrm{IC}_{50}\right)$ in phenolic extracts of Quercus leaves were calculated to determine the root exudates ability of herbaceous species to influence the microbiota in the plant-pathogen infection. The AA was determined by the 2,2-diphenyl-1-picrylhydrazyl radical (DPPH) (SigmaAldrich, Madrid, Spain; [35]). Crude extracts (5 volumes) were mixed with 95 volumes of DPPH $3.35 \mathrm{mM}$ in methanol. In the control tube, the extract volume was replaced by methanol. The mixture was stirred gently and maintained in the dark and at room temperature for $24 \mathrm{~h}$. After incubation, the absorbance was measured at $550 \mathrm{~nm}$. Trolox (Sigma-Aldrich, Madrid, Spain) was used as standard and results were expressed as micromole of Trolox equivalents (T.E.) per milligrams of lyophilized sample. AA was expressed as a percentage inhibition of DPPH radical, and calculated from the equation: Scavenging activity $(\%)=(($ Abs control-Abs sample $) / A b s$ control $) \times 100$. IC 50 values were determined from the plotted graphs as scavenging activity against the concentration of the extracts. These values are defined as inhibitory concentration of the extract necessary to decrease the initial DPPH radical concentration by 50\% and they are expressed in micrograms per milliliters.

Low molecular-weight phenolic compounds of the phenolic extracts from Quercus leaves were identified by high performance liquid chromatography (HPLC) to determine which ones are involved in the Quercus defensive response facing P. cinnamomi infection and the effect of the presence of herbaceous plants on their production. They were analysed on an Agilent 1200 liquid chromatograph instrument (Agilent Technologies, Santa Clara, CA, USA). The standard compounds used for their identification were gallic, protocatechuic, p-hydroxyphenyl, p-hydroxybenzoic, vanillic, caffeic, syringic, p-coumaric, ferulic, ellagic and salicylic acids; vescalagine, castalagine, catechin, aesculetin, epicatechin, vanillin, rutin-hydrate, myricetin, eriodictyol, quercetin, naringenin, kaempferol, syringaldehyde, and coniferyl and sinapyl aldehyde. The column used was Poroshell 120 SB-C18 (100 nm $\times 4.6 \mathrm{~mm} \times 2.7 \mu \mathrm{m}$; Agilent Technologies, Santa Clara, CA, USA) and the mobile phases were water $(0.1 \%$ formic acid, solvent $A)$ and methanol $(0.1 \%$ formic acid, solvent $\mathrm{B}$ ). The gradient employed was the following: $0 \mathrm{~min}, 0 \% \mathrm{~B} ; 1 \mathrm{~min}, 5 \% \mathrm{~B} ; 16 \mathrm{~min}$, $20 \% \mathrm{~B} ; 30 \mathrm{~min} 50 \% \mathrm{~B} ; 36 \mathrm{~min}, 100 \% \mathrm{~B}$ and was maintained for $5 \mathrm{~min}$ before returning to initial conditions. A flow rate of $1 \mathrm{~mL}$ per minute was used together with an injection volume of $0.5 \mu \mathrm{L}$ and column temperature was fixed to $30^{\circ} \mathrm{C}$. Detection was performed with a diode-array detector $(255,280,305,345$ and $370 \mathrm{~nm})$ and fluorescence detector $(E x=275 \mathrm{~nm}, E \mathrm{~m}=315 \mathrm{~nm})$ and peak areas were used as analytical response.

The effect of Quercus species (Q. faginea and Q. suber), herbaceous species (D. tenuifolia, E. vesicaria and L. luteus) and their interactions on Quercus chemical defences (total phenols TPC, total tannins TTC and condensed tannins CTC), antioxidant activity (AA and $\mathrm{IC}_{50}$ ) and the major low molecular weight compounds in phenolic extracts (gallic acid GA, vescalagine Vesc., castalagine Cast., Catechin and ellagic acid EA) were analysed through a general linear model (GLM) using Tukey's test $(p<0.05)$ for significant differences of means. Quercus and herb species were used as random factors and the TPC, TTC, CTC, AA, IC 50 and the major low molecular weight compounds were used as dependent variables. Data were analysed to check normality (by Kolmogorov-Smirnov test) and homoscedasticity (through Levene's test). Interactions between Quercus and herb species were also included in the model. Statistical analyses were performed using the Statistica v10 software. 


\section{Results}

3.1. In Vitro Assessment of the Allelopathic Effect in the Activity of Phytophthora cinnamomi

The most effective method of ARE extraction was M2 (ARE extracted by heat inactivation of enzymes) due to its greater inhibition of mycelial growth $(p<0.001$ Figures $1-3$, Table 1). The species with the highest allelopathic capacity were $D$. tenuifolia and E. vesicaria for their greater inhibition of mycelial growth and the non-viability of the reproductive structures of $P$. cinnamomi in the AREs presence $(p<0.001)$. There were significant differences in mycelial growth between these two species and $R$. raphanistrum (Tukey's test $p<0.001$ ) but not between $D$. tenuifolia and E. vesicaria (Tukey's test $p>0.05$ ). The first two species caused a mycelial growth inhibition of up to $67.5 \%$ compared to the control. $R$. raphanistrum showed the lowest allelopathic activity (up to $55.73 \%$ growth inhibition).

Sporangia and chlamydospore production with AREs application showed reduction compared to the control, especially with $D$. tenuifolia $(100 \%$ inhibition in both, $p<0.001)$. Significant inhibition of zoospore viability was observed on D. tenuifolia ARE $(83.75 \%$ versus control, $p<0.001)$. Generally, the P. cinnamomi mycelium in the presence of studied AREs showed lysis of the cytoplasm after six days and total destruction with $D$. tenuifolia ARE after 12 days (Figure 3). Inhibition in chlamydospore production was $100 \%$ with D. tenuifolia ARE.

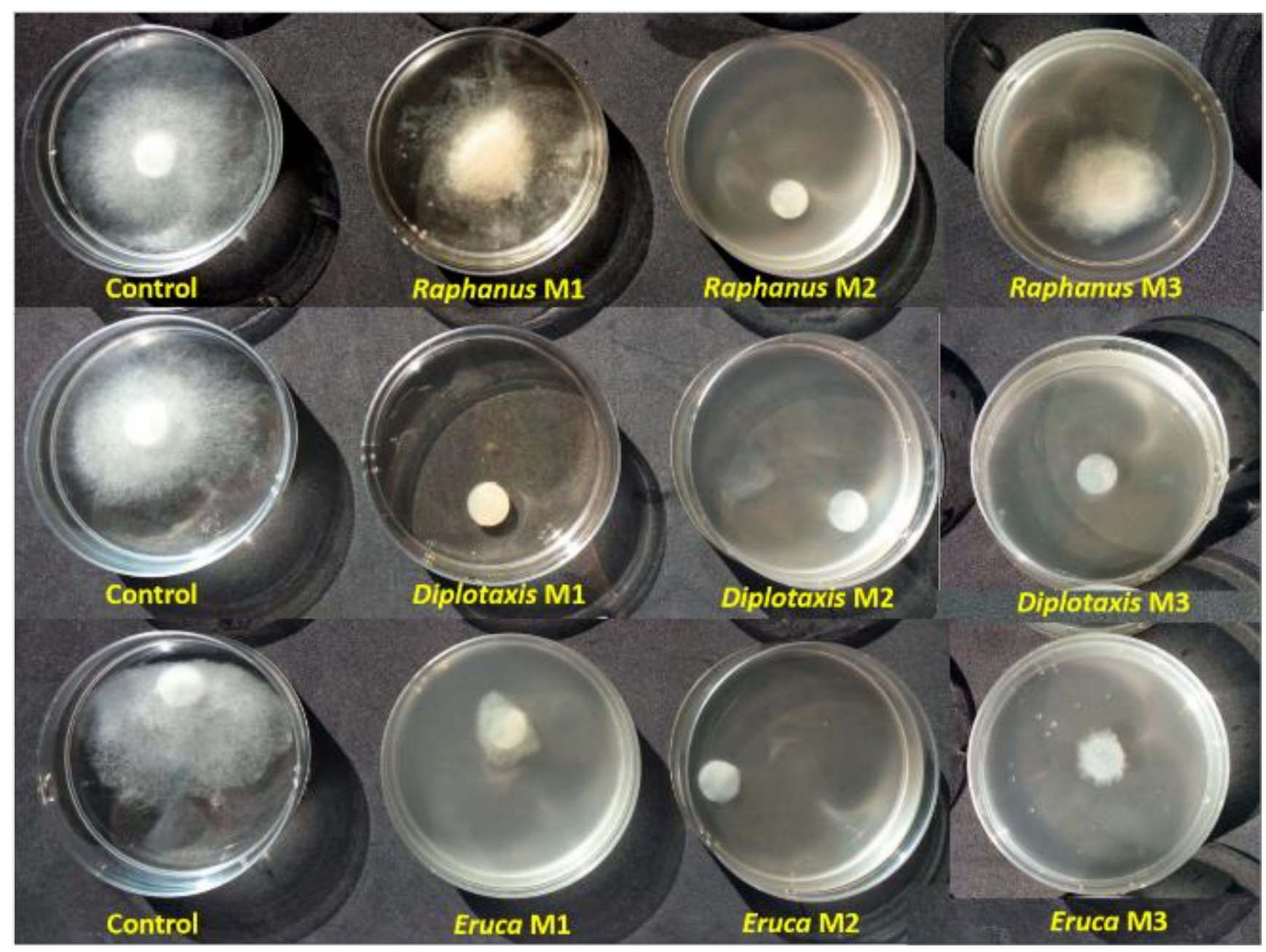

Figure 1. Inhibitory effect of different AREs extracted by three methods (M1, M2 and M3) on Phytophthora cinnamomi mycelial growth in V8 broth after 12 days at $25^{\circ} \mathrm{C}$ in the dark. Method 2 (M2) was the most effective in all ARE, and in particular with D. tenuifolia ARE. 


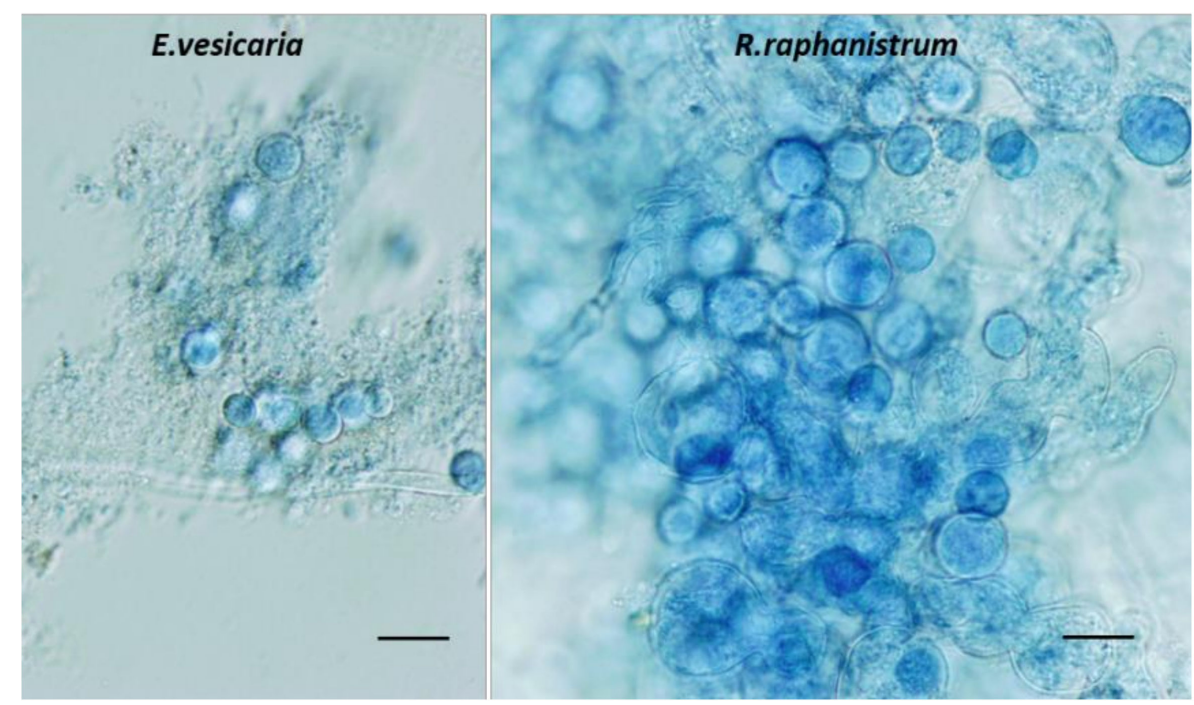

Figure 2. Zoospores encystment of Phytophthora cinnamomi in a non-sterile soil extract in presence of E. vesicaria and R. raphanistrum AREs. Bar $10 \mu \mathrm{m}$.

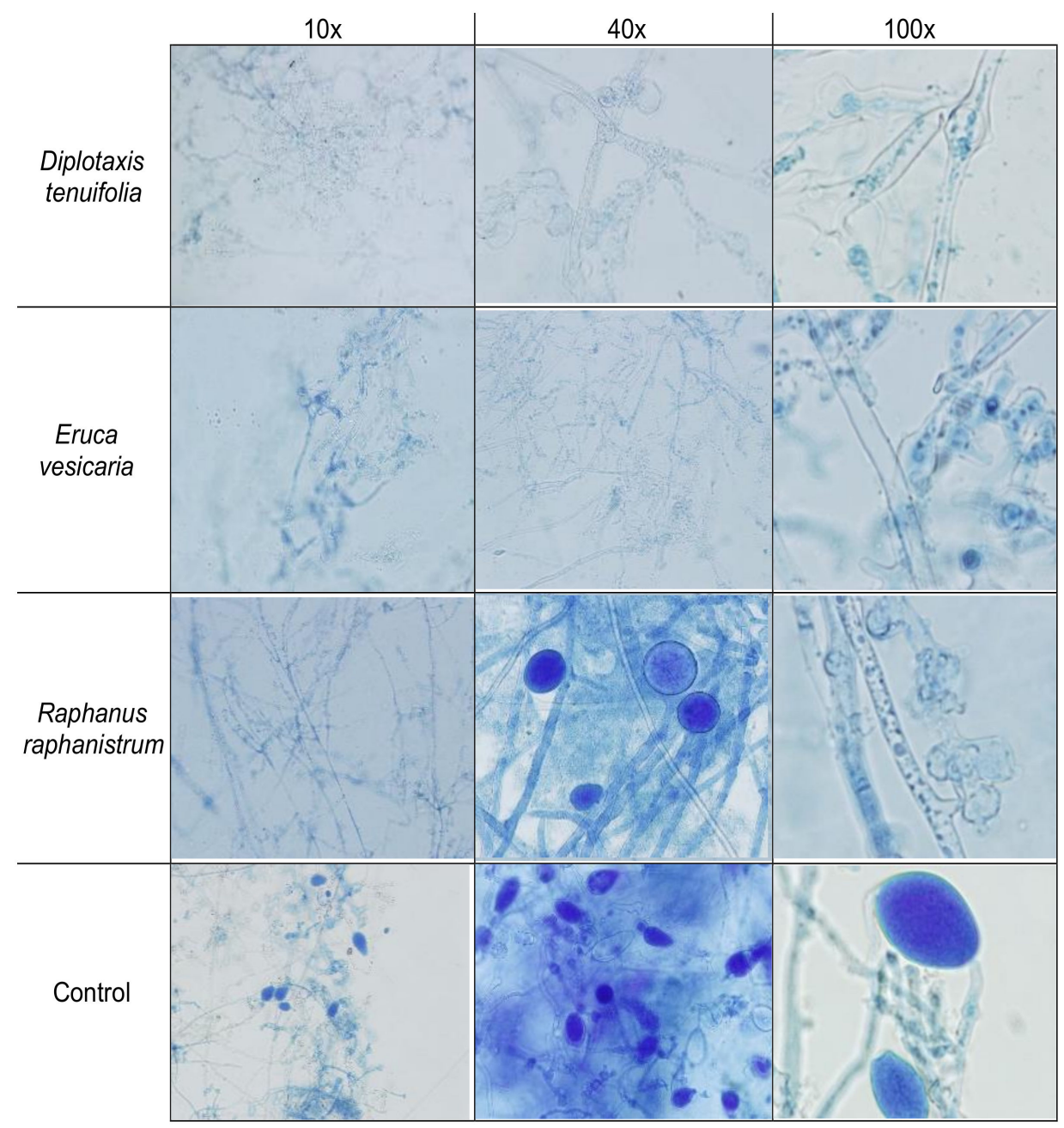

Figure 3. Mycelial growth and sporangia production. Although AREs (M2) of all species showed direct lysis of the sporangia and hyphae, the D. tenuifolia ARE showed the highest inhibition of P. cinnamomi activity ( $100 \%$ sporangia and chlamydospore inhibition, $p<0.001)$. 
Table 1. Allelopathic effects of AREs on Phytophthora cinnamomi structures (percentages are the mean and standard errors of six replicates per method and species).

\begin{tabular}{|c|c|c|c|c|c|c|c|c|c|}
\hline Allelopathic Species & \multicolumn{3}{|c|}{ Diplotaxis tenuifolia } & \multicolumn{3}{|c|}{ Eruca sativa } & \multicolumn{3}{|c|}{ Raphanus raphanistrum } \\
\hline ARE's pH & & 5.38 & & & 5.59 & & & 4.94 & \\
\hline Method & M1 & M2 & M3 & M1 & M2 & M3 & M1 & M2 & M3 \\
\hline Inhib. (\%) mycelial growth & $58.0 \pm 0.5$ & $67.5 \pm 0.2$ & $65.3 \pm 0.3$ & $62.4 \pm 0.2$ & $64.4 \pm 0.2$ & $63.5 \pm 0.01$ & $1.1 \pm 0.01$ & $55.7 \pm 0.01$ & $19.9 \pm 0.1$ \\
\hline $\begin{array}{l}\text { Inhib. }(\%) \text { zoospore } \\
\text { germination }\end{array}$ & & $83.7 \pm 0.6$ & & & $62.5 \pm 0.3$ & & & $37.5 \pm 1.2$ & \\
\hline $\begin{array}{c}\text { Inhib. (\%) sporangia after } \\
6 \text { days }\end{array}$ & & 100 & & & $76.9 \pm 0.5$ & & & $30.7 \pm 2.5$ & \\
\hline $\begin{array}{l}\text { Inhib. (\%) sporangia after } \\
12 \text { days }\end{array}$ & & 100 & & & $83.3 \pm 0.3$ & & & $33.3 \pm 1.2$ & \\
\hline $\begin{array}{c}\text { Inhib. (\%) chlamydospores } \\
\text { after } 12 \text { days }\end{array}$ & & 100 & & & $89.6 \pm 0.4$ & & & $44.3 \pm 2.7$ & \\
\hline
\end{tabular}

In presence of E. vesicaria and R. raphanistrum AREs, released zoospores showed a high and quick immobilization (Figure 2) with encystment, compared to the control, in which zoospores were highly mobile for a long time. This result seems to be a good indicator of a reduction in P. cinnamomi activity with AREs of E. vesicaria and R. raphanistrum. Zoospore encystment in the presence of $D$. tenuifolia could not be reported because ARE from that species completely inhibited sporangia production.

\subsection{In Vivo Evaluation of the Herbaceous Species Effect on Quercus Seedlings in P. cinnamomi- Infested Soil}

The presence of these herbaceous plants had a significant effect on the production of chemical defences on Quercus grown in P. cinnamomi-infested soil $(p<0.05$, Table 2$)$. The AA in Quercus phenolic extracts was also modified in the presence of these herb species (Table 2). The levels of chemical defences in P. cinnamomi-susceptible Quercus species decreased especially with D. tenuifolia and E. vesicaria, and the Quercus plants remained alive (Figure 4, Table S3 Supplementary Materials).

Table 2. Effect of Quercus species (Q. faginea and Q. suber), herbaceous species (D. tenuifolia, E. vesicaria and L. luteus) and their interactions on Quercus chemical defences (total phenols TPC, total tannins TTC and condensed tannins CTC), antioxidant activity (AA and $\mathrm{IC}_{50}$ ) and the major low molecular weight compounds in phenolic extracts (gallic acid GA, vescalagine Vesc., castalagine Cast., Catechin and ellagic acid EA).

\begin{tabular}{cccc}
\hline Quercus Species & Herbaceous Species & $\begin{array}{c}\text { Quercus Species * } \\
\text { Herbaceous Species }\end{array}$ \\
\hline df & 1 & 3 & 3 \\
TPC & 0.53 & $62.03^{*}$ & $72.48^{*}$ \\
TTC & $309.81^{*}$ & $1970.47^{*}$ & $12.82^{*}$ \\
CTC & $1467.94^{*}$ & $433.12^{*}$ & $220.14^{*}$ \\
AA & $238.95^{*}$ & $77.66^{*}$ & $64.03^{*}$ \\
IC 50 & $963.16^{*}$ & $46.09^{*}$ & 92.43 \\
GA & $10.31^{*}$ & 1.20 & $10.19^{*}$ \\
Vesc. & $59.90^{*}$ & $29.30^{*}$ & $109.00^{*}$ \\
Cast. & $37.76^{*}$ & $77.96^{*}$ & $25.43^{*}$ \\
Catechin & $6730.80^{*}$ & $100.48^{*}$ & $93.07^{*}$ \\
EA & $1698.40^{*}$ & $8.09^{*}$ & $29.60^{*}$ \\
\hline
\end{tabular}

F-values are shown along with statistical significance ${ }^{*} p<0.05$.

Overall, in the three major phenolic groups (total phenol content TPC, total tannin content TTC and condensed tannin content CTC) and for the Quercus species tested (3 phenolic groups $\times 2$ Quercus species), 3/6 were in accordance with predictions (suppressed chemical response when grown with the two allelopathic species and elevated response when grown with L. luteus or no companion plant [control]); 1/6 showed no clear pattern; and 2/6 showed suppression of chemical response with all three species of companion plants. 
From the HPLC analysis for the low molecular weight compounds in Quercus leaves, five of them were determinant: gallic acid, vescalagine, castalagine, catechin and ellagic acid. These compounds showed significant differences between treatments (Tukey test $p<0.05$, Table 2 and Table S3 from Supplementary Materials). In these five low molecular weight phenolic compounds assessed for the two Quercus species (10 combinations), 1/10 was in accordance with predictions (suppressed chemical response when grown with the two allelopathic species and elevated response when grown with L. luteus or no companion plant [control]); 6/10 showed no clear pattern; 2/10 showed suppression of chemical response with all three species of companion plants; and 1/10 showed enhance chemical response with all three species of companion plants.

Regarding antioxidant activity (AA) measured in Quercus leaves, both the herbaceous and Quercus and their interaction showed significant differences $(p<0.001)$. AA was very high in Q. suber with L. luteus, high in the control, intermediate in Quercus grown with the allelopathic herbaceous and very low in the $Q$. faginea with L. luteus. The half maximal inhibitory concentration (IC50) showed, as might be expected from its ability to measure the effectiveness of a compound's antioxidant capacity, the inverse pattern to AA. The effect of both Quercus and herbaceous plants showed significant differences $(p<0.001)$ in the IC50 (Figure 4, Table S3 Supplementary Materials).

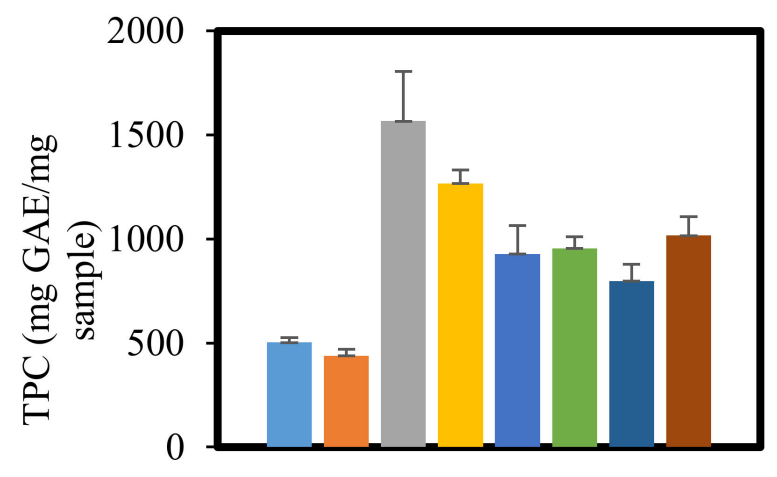

(a)

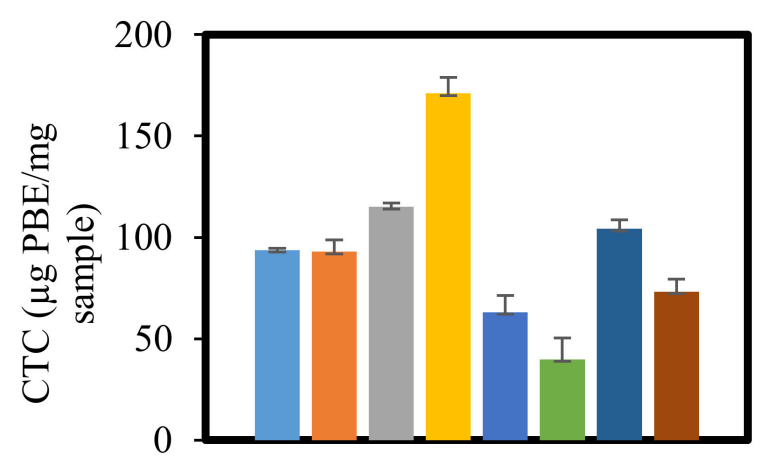

(c)

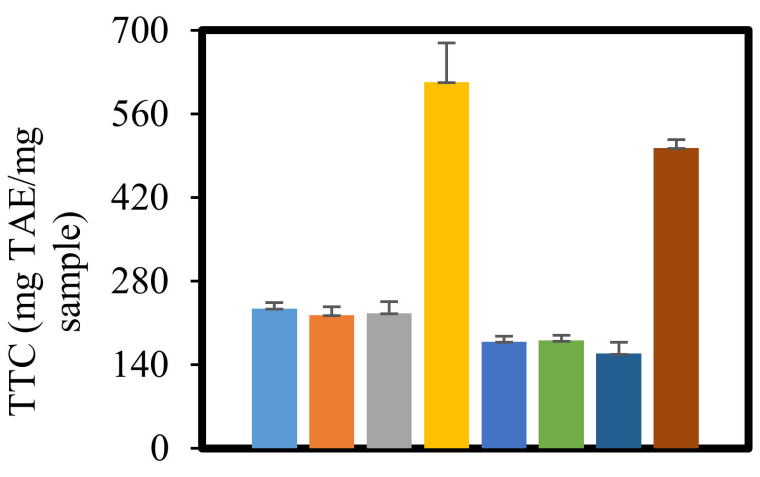

(b)

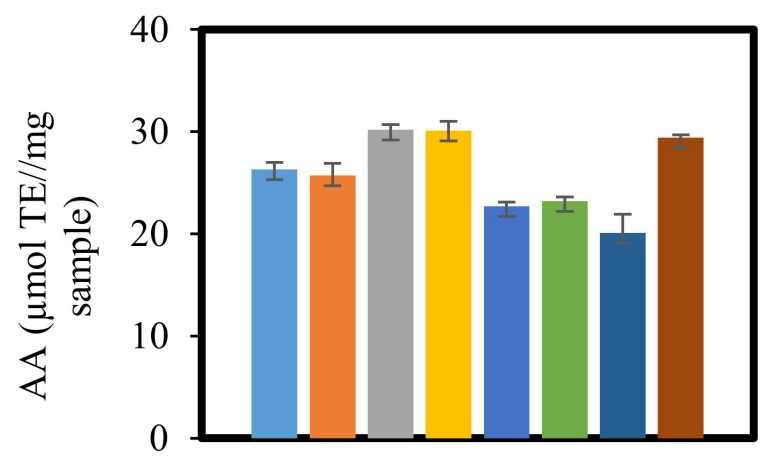

(d)

Figure 4. Cont. 


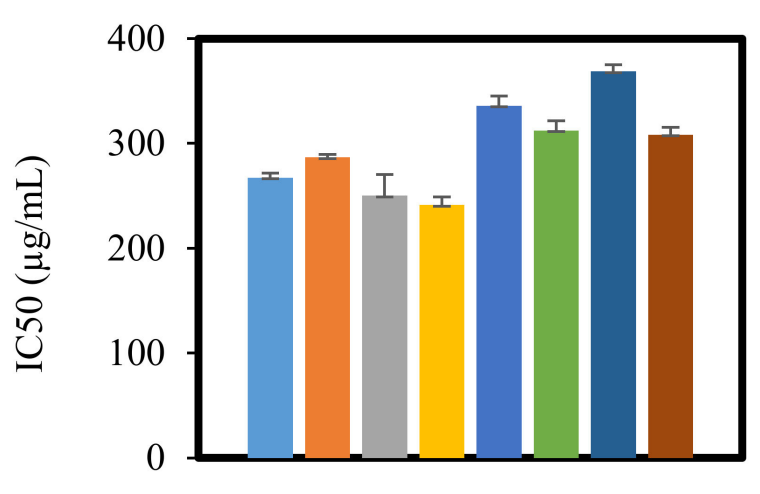

(e)

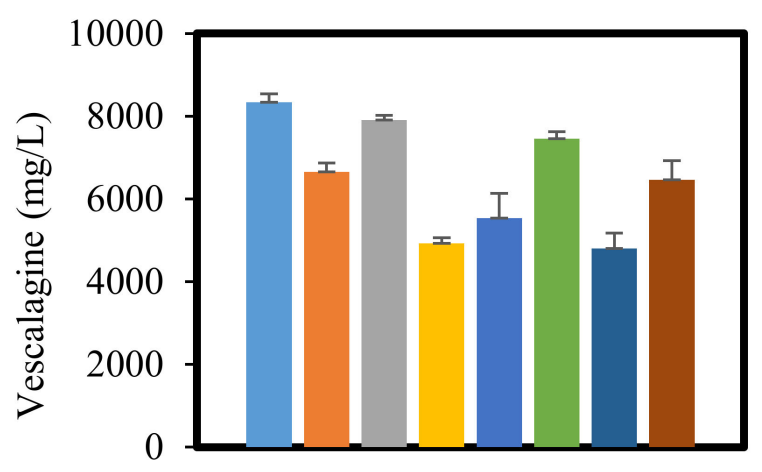

(g)

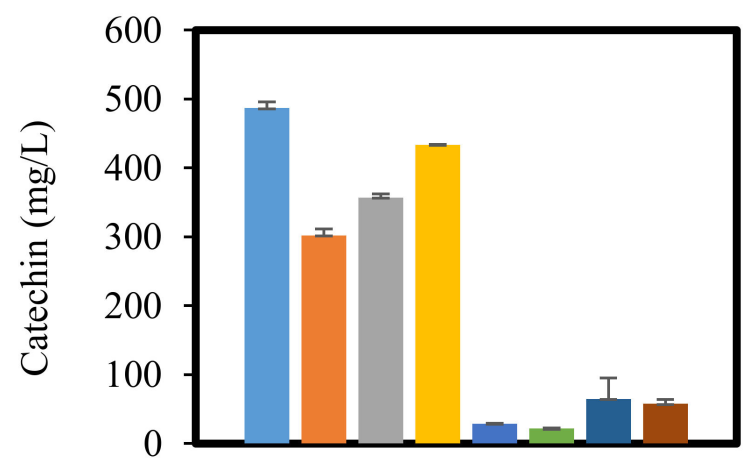

(i)

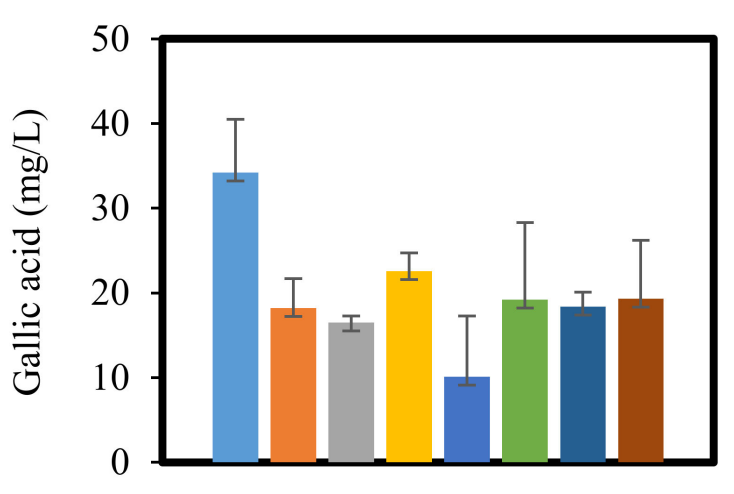

(f)

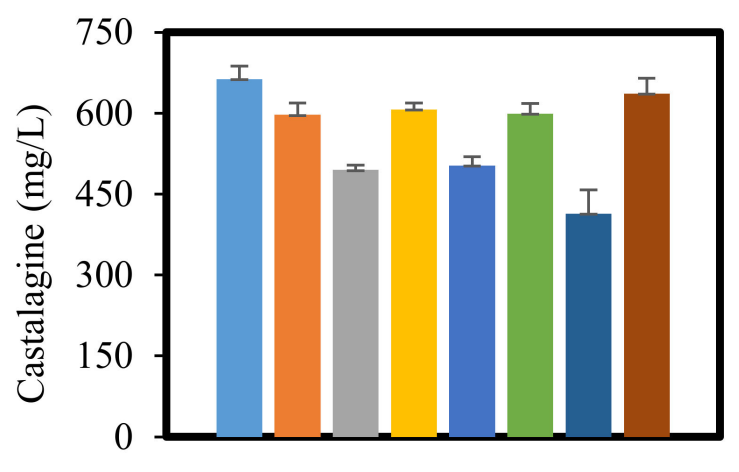

(h)

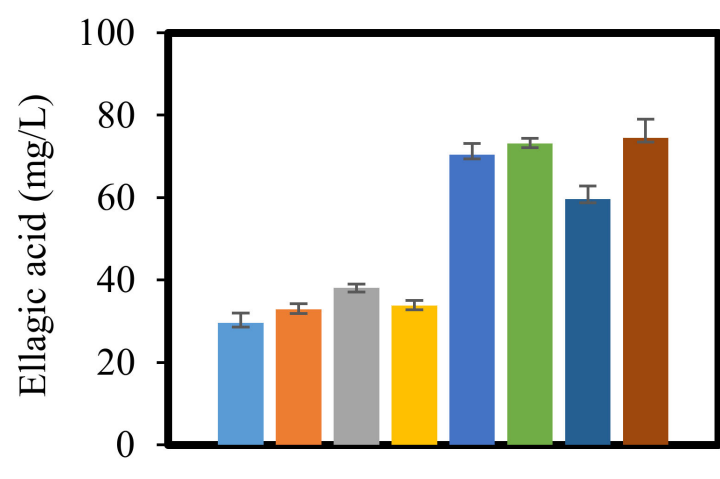

(j)

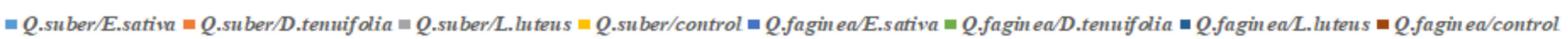

Figure 4. Chemical composition of phenolic extracts from Quercus leaves grown with allelopathic root exudates and Phytophthora cinnamomi infection. (a) Total phenols (TPC), (b) total tannins (TTC), (c) condensed tannins (CTC), (d) antioxidant activity (AA), (e) the half maximal inhibitory concentration $\left(\mathrm{IC}_{50}\right)$ and the major low molecular weight compounds in phenolic extracts (f) gallic acid, (g) vescalagine, (h) castalagine, (i) catechin and (j) ellagic acid. Means are shown \pm standard deviation.

\section{Discussion}

\subsection{Anti-Phytophthora Effects with AREs}

AREs prepared by method M2 (maceration in hot water to inactivate myrosinase) showed the strongest activity against $P$. cinnamomi. This result was expected because the method followed had been tested in Sampaio [18] and Moreira et al. [21] with conclusive results. 
Regarding the species tested, the ARE of D. tenuifolia showed a very high effectiveness, with $67.55 \%$ inhibition of mycelial growth and $100 \%$ inhibition of sporangia production, in accordance with Moreira et al. [21], although the percentage of inhibition in the aforementioned study was higher ( $83 \%$ for a $75 \%$ ARE concentration). Previous studies of P. cinnamomi inhibition by E. vesicaria $[18,19,21]$ and $R$. raphanistrum $[18,21]$ also confirm their allelopathic effect. E. vesicaria, whose main glucosinolates are aliphatic (glucoraphanin, glucosativin and glucoerucin) showed a high inhibition, but not the complete non-viability of its reproduction structures, according with what was discovered by Ríos et al. [19]. $R$. raphanistrum showed lower inhibition values than the two previous species and very similar to that obtained by Moreira et al. [21] for the mycelial growth of P. cinnamomi.

The total inhibition of P. cinnamomi sporangia production by applying the D. tenuifolia ARE is a very important advance demonstrated in this study. However, the in vitro conditions of the test must be taken into account and new experiments could be conducted under field conditions. Although E. vesicaria does not completely inhibit the production of sporangia, a very important reduction in the mobility of zoospores was observed when they are released in the presence of the extract. Zoospores lead to primary infections, so this reduction is key in limiting the spread of the disease.

\subsection{In Vivo Evaluation of the Herbaceous Species Effect on Quercus Seedlings in P. cinnamomi- Infested Soil}

The Quercus phenolic defences showed significant differences depending on the companion allelopathic herbaceous species with those that grew together in P. cinnamomiinfested soil. The allelopathic effect associated with the lowering of chemical defences in Quercus suggests a suppression of P. cinnamomi levels in the soil. Furthermore, the increase in Quercus chemical defences grown with a P. cinnamomi highly susceptible species (L. luteus) may due to the stimulation of P. cinnamomi levels in the soil.

The lowest TPC and CTC values were reached with E. vesicaria and D. tenuifolia in both Quercus. The CTC were found used in other studies as a good indicator of the $P$. cinnamomi response [14]. In this work, CTC were always higher in Q. suber than in Q. faginea, which is more tolerant to P. cinnamomi [14]. With L. luteus, also highly susceptible to the pathogen [36], both Quercus species increased their defensive levels against $P$. cinnamomi, although the increase was greater in Q. suber (susceptible to P. cinnamomi) than in Q. faginea (tolerant to P. cinnamomi).

There are previous studies on the increase of TPC and CTC in Q. ilex infected by P. cinnamomi $[14,37]$. If we consider the chemical defence production in Quercus as a response to the attack they are suffering, it is expected that the Quercus species studied here also increase their defensive levels. However, in the presence of E. vesicaria and D. tenuifolia, aforementioned levels decreased with respect to the control (without the presence of herbaceous plants). This suggests that the allelopathic relationship of the herb species with the pathogen reduces the inoculum levels of P. cinnamomi also in vivo conditions and therefore, the magnitude of the defensive response in Quercus is reduced.

It is known that interactions among plants are frequently controlled by root exudates, some of which have activity against microorganisms [38]. In general, the high inhibitory activity of $D$. tenuifolia and E. vesicaria also acted in vivo conditions but we do not know if it was through their root exudates or if it is due to other factors involved in the joint growth of herbaceous plants with Quercus, such as competition between them during the first years. However, a diminished chemical response in Quercus was suggestive of reduced levels of P. cinnamomi. This could be explained by the release of secondary metabolites in allelopathic root exudates, or also by the facilitation of inhibitory soil bacteria against the pathogen. In addition, this study shows that the presence of these allelopathic herbaceous plants growing in P. cinnamomi-infested soil reduced the defence level of $Q$. suber, which is susceptible to P. cinnamomi. Therefore, these herb species reduce the chemical defence costs in TPC and CTC production against the pathogen's attack. No previous studies are known with these species to establish comparisons, but the complex analysis of the 
herb-tree-pathogen interactions $[39,40]$ should be continued to better understand the role of each component in that relationship.

As for the low molecular weight phenolic compounds, these were always minimum in Q. faginea and maximum in Q. suber (except ellagic acid). Ockels et al. [41] studied the differences in the phenolic chemical compounds of phloem tissue of Q. agrifolia infected with $P$. ramorum and tested gallic acid in vitro bioassays, finding a strong dose-dependent inhibitory effects against $P$. ramorum and $P$. cinnamomi. Del Río et al. [42] also associated higher levels of catechin with greater tolerance to the genus Phytophthora in olive trees. Higher production of these defences would indicate the response to a higher attack caused by the infection. In the susceptible species (the cork oak) the accompanying allelopathic plant that less increases the levels of defences will be the most effective because it reduces $P$. cinnamomi infection. This happened with $D$. tenuifolia, which confirms its inhibitory capacity against the pathogen observed in vitro conditions. However, ellagic acid showed the opposite pattern, and was higher in Q. faginea without allelopatic plants and lower in $Q$. suber with E. vesicaria. This compound seems to be directly related to tolerance to Phytophthora infection in other Quercus species [41,43-45], although its levels in the presence of allelopathic herbaceous plants do not show a clear pattern, which suggests that there are other soil organisms (probably bacteria) also highly conditioned by plant-pathogen interaction. The authors consider the need to have a better knowledge of the surrounding microbiota relationships in order to explain its role.

Regarding AA in Quercus leaves, the highest one was found in Q. suber seedlings that grew together with L. luteus (both species susceptible to P. cinnamomi). The lowest AA was that of Q. faginea with L. luteus (Quercus species more tolerant to P. cinnamomi than Q. suber). Antioxidants protect biological systems against reactions or processes that can produce harmful effects in the individual. In a weakened system, as is the case of the Q. suber with L. luteus growing in a P. cinnamomi infested soil, it is to be expected that there would be more free radicals and therefore, a greater AA would be induced. However, in scenarios with more tolerant to $P$. cinnamomi-species, such as Q. faginea, the expected AA would be lower. To strengthen the defensive response to biotic stress, seedlings induce a hypersensitive response that consists of programmed cell death to ensure the plant survival. When stress decreases, AA also drops [46]. In our study, when the Quercus species most susceptible to $P$. cinnamomi grew with $D$. tenuifolia and E. vesicaria, AA decreased, showing lower stress levels. In $Q$. faginea, this level also decreased in the presence of allelopathic species. Therefore, the presence of these allelopathic species generated a protective effect on Quercus seedlings, reducing their stress levels facing the pathogen infection. By its own definition, the higher the $\mathrm{AA}$, the lower the $\mathrm{IC}_{50}$ and therefore, the more effective the exudate evaluated. However, both the $\mathrm{AA}$ and the $\mathrm{IC}_{50}$ in this test were calculated from the phenolic extract of Quercus leaves, so their values are an indirect measure of the effectiveness of the allelopathic herbs. But it would be very interesting to do a chemical characterization of their root exudates to discriminate other effects that could be involved in these plant-pathogen interactions.

The chemical composition of different plant extracts of the Diplotaxis, Eruca and Raphanus genera has been extensively studied in nutrition for its antioxidant and bactericidal properties [47-49]. Rarer is the chemical characterization of these species for biological control against plant pathogens. However, Brassicaceae family has been specially studied for its glucosinolate content for biofumigation. This is a widely used biological control tool against several pathogens. Ríos et al. [19] screened various brassicaceous plants (D. tenuifolia was not evaluated) to identify the most suitable and the compounds responsible for the inhibitory allelochemical activity of P. cinnamomi. They demonstrated the biocidal action on P. cinnamomi of rich in sinigrin-species, such as B. juncea and $B$. carinata (see also [50-52]), while in others glucosinolates different from sinigrin (such as E. vesicaria) only a fungistatic effect was obtained. However, later in vivo tests to control the disease in cork oak with $B$. carinata pellets proved their significant effectiveness only when combined with calcium carbonate application [22]. In fact, all the authors agree on 
an integrated fight against the oak decline. Furthermore, the application of Brassicas uses high amounts of biomass and is not feasible in some lands due to orographic limitations. The novel approach of this work proposes the enrichment of pastures with allelopathic species against P. cinnamomi. The inoculum would not be eradicated from the soil, but the disease spread could be dimmed, increasing the tolerance of several species in Iberian wood pastures. The incorporation in the field of native plants capable of reducing the P. cinnamomi infective activity through their natural root exudates shows high potential in the possible control of the pathogenic activity with a sustainable management in these agrosilvopastoral systems. Furthermore, the use of allelopathic plants has the advantage that they usually contain more than one antipathogenic compound, which hinders the development of resistance of pathogens [40]. However, it should still be deepened in several issues such as the knowledge of these relationships, their action and release in the field, the most recommended doses to avoid toxicity in other plants and whether other surrounding microorganisms such as bacteria are involved in them.

\section{Conclusions}

This study confirms the existence of allelopathic relationships capable of inhibiting the infective pathogen activity in vitro and in vivo conditions. From the three species studied, the ARE of $D$. tenuifolia was especially suited for its complete inhibition of the P. cinnamomi sporangia production in vitro. In addition, when these herb plants grew together with Quercus seedlings in P. cinnamomi-infested soils, the Quercus chemical defences lowered but plants did not die, which could be the result of a protective effect of the allelopathic species against infection. However, it would be necessary to explore the complex of soil microorganisms present in this allelopathic relationship for its better management before possible testing and application in the field.

Supplementary Materials: The following are available online at https:/ /www.mdpi.com/1999-4907/ 12/3/285/s1: Table S1. Effect of AREs species (D. tenuifolia- D, E. vesicaria- E and R. raphanistrum- R), sources (field/greenhouse) and their interactions on chemical defences (total phenols $\mathrm{Tp}$, total tannins $\mathrm{Tt}$ and condensed tannins $\mathrm{Ct}$ ) and antioxidant activity (AA and $\mathrm{IC}_{50}$ ). Table S2. Chemical composition of aqueous root extracts according to species and source. Total phenols (Tp), total tannins $(\mathrm{Tt})$, condensed tannins $(\mathrm{Ct})$, antioxidant activity $(\mathrm{AA})$ and the half maximal inhibitory concentration $\left(\mathrm{IC}_{50}\right)$. Means and standard deviation. Table S3. Chemical composition of phenolic extracts from Quercus leaves grown with allelopathic root exudates and Phytophthora cinnamomi infection. Total phenols (Tp), total tannins (Tt), condensed tannins (Ct), antioxidant activity (AA), the half maximal inhibitory concentration $\left(\mathrm{IC}_{50}\right)$ and the major low molecular weight compounds in phenolic extracts (gallic acid GA, vescalagine Vesc., castalagine Cast., Catechin and ellagic acid EA). Means are shown \pm standard deviation.

Author Contributions: Conceived, designed and performed the experiments: M.R.-R., B.G.-C., I.M.C., J.A.P. and A.C.M. Analysed the data: M.R.-R., B.G.-C. and A.C.M. Contributed reagents/ materials/analysis tools and wrote the paper: all authors. All authors have read and agreed to the published version of the manuscript.

Funding: This work has been partially funded by the "Cross-border cooperation project for the integral assessment of dehesa and montado PRODEHESA-MONTADO", a project financed by the European Regional Development Fund (ERDF) through the INTERREG V-A Spain-Portugal Program (POCTEP) 2014-2020; and by the Spanish National Institute for Agriculture and Food Research and Technology (INIA)/CICYTEX funds through the grant FPI-INIA to Manuela Rodríguez.

Institutional Review Board Statement: Not applicable.

Informed Consent Statement: Not applicable.

Data Availability Statement: The datasets generated during and/or analysed during the current study are available from the corresponding author on reasonable request. 
Acknowledgments: Authors would like to thank the ICMC, INIAV and the staff support from the Project "Declínio do Montado no Alentejo" (PDR2020-101-031496), and specially Fernando Pulido, from the UEX, for the technical assistance received and for the critical review of this article.

Conflicts of Interest: The authors declare no conflict of interest.

\section{References}

1. Molisch, H. Der Einfluss einer Pflanze auf die andere Allelopathie. Nature 1937, 141. [CrossRef]

2. Rice, E.L. Allelopathy, 2nd ed.; Academic Press: New York, NY, USA, 1984.

3. Farooq, M.; Jabran, K.; Cheema, Z.A.; Wahid, A.; Siddique, K.H. The role of allelopathy in agricultural pest management. Pest Manag. Sci. 2011, 67, 493-506. [CrossRef] [PubMed]

4. Ferguson, J.J.; Rathinasabapathi, B.; Chase, C.A. Allelopathy: How Plants Suppress Other Plants; University of Florida: Gainesville, FL, USA, 2013; pp. 1-5. Available online: http:/ / edis.ifas.ufl.edu/hs186 (accessed on 25 February 2021).

5. Rizvi, S.J.H.; Haque, H.; Singh, U.K.; Rizvi, V. A discipline called allelopathy. In Allelopathy: Basic and Applied Aspects; Rizvi, S.J.H., Rizvi, H., Eds.; Chapman \& Hall: London, UK, 1992; pp. 1-10.

6. Singh, H.; Batish, D.; Hohli, R. Allelopathy in Agroecosystems: An Overview; The Haworth Press, Inc.: Pennsylvania, PA, USA, 2001; pp. 1-42.

7. Brasier, C.M. Oak tree mortality in Iberia. Nature 1992, 360, 359. [CrossRef]

8. Hardham, A.R.; Blackman, L.M. Phytophthora cinnamomi. Mol. Plant Pathol. 2018, 19, 260-285. [CrossRef]

9. Dunstan, W.A.; Rudman, T.; Shearer, B.L.; Moore, N.A.; Paap, T.; Calver, M.C.; Dell, B.; Hardy, G.E.S.J. Containment and spot eradication of a highly destructive, invasive plant pathogen (Phytophthora cinnamomi) in natural ecosystems. Biol. Invasions 2010, 12, 913-925. [CrossRef]

10. Rodríguez-Molina, M.C.; Torres-Vila, L.M.; Blanco-Santos, A.; Nunez, E.J.P.; Torres-Álvarez, E. Viability of holm and cork oak seedlings form acorns sown in soils naturally infected with Phytophthora cinnamomi. For. Pathol. 2002, 32, 365-372. [CrossRef]

11. Sánchez, M.E.; Andicoberry, S.; Trapero, A. Pathogenicity of three Phytophthora spp. causing late seedling rot of Quercus ilex ssp. ballota. For. Pathol. 2005, 35, 327-334. [CrossRef]

12. Pérez-Sierra, A.; López-García, C.; Leon, M.; García-Jiménez, J.; Abad-Campos, P.; Jung, T. Previously unrecorded low-temperature Phytophthora species associated with Quercus decline in a Mediterranean forest in Eastern Spain. For. Pathol. 2013, 43, 331-339. [CrossRef]

13. Solla, A.; Milanovic, S.; Gallardo, A.; Bueno, A.; Corcobado, T.; Cáceres, Y.; Morcuende, D.; Quesada, A.; Moreno, G.; Pulido, F.J. Genetic determination of tannins and herbivore resistance in Quercus ilex. Tree Genet. Genomes 2016, 12, 117. [CrossRef]

14. Gallardo, A.; Morcuende, D.; Solla, A.; Moreno, G.; Pulido, F.J.; Quesada, A. Regulation by biotic stress of tannins biosynthesis in Quercus ilex: Crosstalk between defoliation and Phytophthora cinnamomi infection. Physiol. Plant 2019, 165, 319-329. [CrossRef] [PubMed]

15. John, J.; Sarada, S. Role of phenolics in allelopathic interactions. Allelopath. J. 2012, 29, 215-230.

16. FAO. Protecting Plantations from Pests and Diseases; Report based on the work of W.M. Ciesla, Forest Plantation Thematic Papers, Working Paper 10; Forest Resources Development Service, Forest Resources Division, FAO: Rome, Italy, 2001; Available online: http:/ / www.fao.org/forestry (accessed on 25 February 2021).

17. Kong, C.H.; Xuan, T.D.; Khanh, T.D.; Tran, H.D.; Trung, N.T. Allelochemicals and signaling chemicals in plants. Molecules 2019, 24, 2737. [CrossRef] [PubMed]

18. Sampaio, A.R. Selecção de Plantas com Efeito Alelopático Para Controlar Phytophthora innamomi Rands. Dissertação Para Obtenção do Grau de Mestre em Engenharia Agronómica-Protecção de Plantas; School of Agriculture, University of Lisbon: Lisbon, Portugal, 2017; p. 71.

19. Ríos, P.; Obregón, S.; González, M.; de Haro, A.; Sánchez, M.E. Screening brassicaceous plants as biofumigants for management of Phytophthora cinnamomi oak disease. For. Path. 2016, 46, 652-659. [CrossRef]

20. Ríos, P.; Obregón, S.; de Haro, A.; Fernández-Rebollo, P.; Serrano, M.; Sánchez, M.E. Effect of Brassica biofumigant amendments on different stages of the life cycle of Phytophthora cinnamomi. J. Phytopathol. 2016, 164, 582-594. [CrossRef]

21. Moreira, A.; Calha, I.; Passarinho, J.; Sampaio, A. Anti-Phytophthora activity of root extracts from herbaceous species. Rev. Ciências Agrárias 2018, 41, 39-47.

22. Rodríguez-Molina, M.C.; Serrano-Pérez, P.; Santiago, R.; Cardillo, E.; Godoy, B.; De Santiago, A. Efecto de la biofumigación con pellets de Brassica carinata en la progresión de la enfermedad causada por Phytophthora cinnamomi en Lupinus luteus. In Libro de Resúmenes XIX Congreso de la Sociedad Española de Fitopatología; SEF: Toledo, Spain, 2018; p. 124.

23. Fenwick, R.G.; Heaney, R.K.; Mullin, W.J. Glucosinolates and their breakdown products in food plants. CRC Crit. Rev. Food Sci. Nutr. 1983, 18, 123-201. [CrossRef]

24. Dunne, C. Control of Sudden Death in Cultivated Proteas from the South West of Western Australia. Ph.D. Thesis, Murdock University, Perth, Australia, 2004.

25. Bialy, Z.; Oleszek, W.; Lewis, J.; Fenwick, G.R. Allelopathic potential of glucosinolates (mustard oil glycosides) and their degradation products against wheat. Plant Soil 1990, 129, 277-281. [CrossRef]

26. Wolf, R.B.; Spencer, G.F.; Kwolek, W.F. Inhibition of velvet leaf (Abutilon thephrasti) germination and growth by benzyl isothiocyanate, a natural toxicant. Weed Sci. 1984, 32, 612-615. [CrossRef] 
27. Fahey, J.W.; Zalcmann, A.T.; Talalay, P. The chemical diversity and distribution of glucosinolates and isothiocyanates among plants. Phytochemistry 2001, 56, 5-51. [CrossRef]

28. Moreira-Marcelino, A.C. Aspectos da Interacção Entre Phytophthora cinnamomi e a Doença do Declínio em Q. suber e Q. rotundifolia; Dissertação para Prestação de Provas de Doutoramento, Faculdade de Engenharia de Recursos Naturais, Universidade do Algarve: Faro, Portugal, 2001; p. 279.

29. Hongju, H. Studies for Growth Adaptation and Identification of Glucosinolates in Various Chinese Brassicas. Ph.D. Thesis, Herbert Utz Verlag-Wissenschaft, München, Germany, 1999.

30. Alkhail, A. Antifungal activity of some extracts against some plant pathogenic fungi. Pak. J. Biol. Sci. 2005, 8, 413-417.

31. Jeffers, S.; Martin, S. Comparison of two media selective for Phytophthora and Phythium species. Plant Dis. 1986, 70, 1038-1043. [CrossRef]

32. Singleton, V.L.; Rossi, J.A. Colorimetry of total phenolics with phosphomolybdic-phosphotungstic acid reagents. Am. J. Enol. Vitic. 1965, 16, 144-158.

33. Schanderl, S.H. Method in Food Analysis; Academic Press: New York, NY, USA, 1970; 709p.

34. Porter, L.J.; Hirstich, L.N.; Chan, B.G. The conversion of procyanidins and prodelphinidins to cyanidin and delphinidin. Phytochemistry 1986, 25, 223-230. [CrossRef]

35. Thaipong, K.; Boonprakob, U.; Crosby, K.; Cisneros-Zevallos, L.; Byrne, D.H. Comparison of ABTS, DPPH, FRAP, and ORAC assays for estimating antioxidant activity from guava fruit extracts. J. Food Compos. Anal. 2006, 19, 669-675. [CrossRef]

36. Serrano, M.; Fernández-Rebollo, P.; De Vita, P.; Carbonero, M.; Sánchez, M.E. The role of yellow lupin (Lupinus luteus) in the decline affecting oak agroforestry ecosystems. For. Pathol. 2011, 4, 382-386. [CrossRef]

37. Rodríguez-Romero, M.; Gallardo, A.; Pulido, F. Geographical and within-population variation of constitutive chemical defences in a Mediterranean oak (Quercus ilex). For. Syst. 2020, 29, e011. [CrossRef]

38. Bais, H.P.; Weir, T.L.; Perry, L.G.; Gilroy, S.; Vivanco, J.M. The role of root exudates in rhizosphere interactions with plants and other organisms. Ann. Rev. Plant Biol. 2006, 57, 233-266. [CrossRef] [PubMed]

39. Cazorla, F.M.; Mercado-Blanco, J. Biological control of tree and woody plant diseases: An impossible task? BioControl 2016, 61, 233-242. [CrossRef]

40. Shuping, D.S.S.; Eloff, J.N. The use of plants to protect plants and food against fungal pathogens: A review. Afr. J. Tradit. Complement. Altern. Med. 2017, 14, 120-127. [CrossRef] [PubMed]

41. Ockels, F.S.; Eyles, A.; McPherson, B.A.; Wood, D.L.; Bonello, P. Phenolic chemistry of coast live oak response to Phytophthora ramorum infection. J. Chem. Ecol. 2007, 33, 1721-1732. [CrossRef]

42. Del Río, J.A.; Baidez, A.G.; Botia, J.M.; Ortuno, A. Enhancement of phenolic compounds in olive plants (Olea europaea L.) and their influence on resistance against Phytophthora sp. Food Chem. 2003, 83, 75-78. [CrossRef]

43. Conrad, A.O.; Rodriguez-Saona, L.E.; McPherson, B.A.; Wood, D.L.; Bonello, P. Identification of Quercus agrifolia (coast live oak) resistant to the invasive pathogen Phytophthora ramorum in native stands using Fourier-transform infrared (FT-IR) spectroscopy. Front. Plant Sci. 2014, 5, 521. [CrossRef] [PubMed]

44. Nagle, A.M.; McPherson, B.A.; Wood, D.L.; Garbelotto, M.; Bonello, P. Relationship between field resistance to Phytophthora ramorum and constitutive phenolic chemistry of coast live oak. For. Pathol. 2011, 41, 464-469. [CrossRef]

45. McPherson, B.A.; Mori, S.R.; Opiyo, S.O.; Conrad, A.O.; Wood, D.L.; Bonello, P. Association between resistance to an introduced invasive pathogen and phenolic compounds that may serve as biomarkers in native oaks. For. Ecol. Manag. 2014, 312, 154-160. [CrossRef]

46. Irfan, M.; Hayat, S.; Bashir, A. Regulation of antioxidant system under biotic stress in plants. In Plant Under Stress; Stadium Press: New Delhi, India, 2011.

47. Mateu, G.; Dimitrova, P.; Petkova, N.; Ivanov, I.; Mihaylova, D. Antioxidant activity and mineral content of rocket (Eruca sativa) plant from Italian and Bulgarian origins. J. Microbiol. Biotech. Food Sci. 2018, 8, 756-759.

48. Nicoletti, R.; Raimo, F.; Miccio, G. Diplotaxis tenuifolia: Biology, production and properties. EJPSB 2007, 1, 36-43.

49. D'Antuono, L.F.; Elementi, S.; Neri, R. Glucosinolates in Diplotaxis and Eruca leaves: Diversity, taxonomic relations and applied aspects. Phytochemistry 2008, 69, 187-199.

50. Ríos, P.; González, M.; Obregón, S.; Carbonero, M.D.; Leal, J.R.; Fernández, P.; de Haro, A.; Sánchez, M.E. Brassica-based seedmeal biofumigation to control Phytophthora cinnamomi in the Spanish "dehesa" oak trees. Phytopathol. Mediterr. 2017, 56, 392-399.

51. Fernández-Rebollo, P.; Carbonero, M.D.; Leal, J.R.; García, A.M.; Ríos, P.; Sánchez, M.E.; Obregón, S.; de Haro, A. Producción, concentración y perfil de glucosinolatos de Brassica carinata y Brassica juncea cultivadas en la dehesa. In Pastos y Forrajes en el Siglo XXI; Cifre., J., Janer, I., Gulias., J., Jaume, J., Medrano, M., Eds.; SEEP: Palma de Mallorca, Spain, 2015; pp. $193-200$.

52. Morales-Rodríguez, C.; Vettraino, A.M.; Vannini, A. Efficacy of biofumigation with Brassica carinata comercial pellets (BioFence) to control vegetative and reproductive structures of Phytophthora cinnamomi. Plant Dis. 2016, 100, 324-330. [CrossRef] 